\title{
The Sodium Channel $\beta 4$ Auxiliary Subunit Selectively Controls Long-Term Depression in Core Nucleus Accumbens Medium Spiny Neurons
}

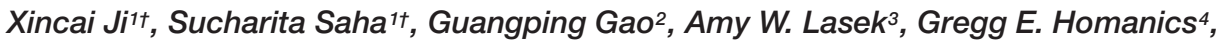 \\ Melissa Guildford ${ }^{1}$, Andrew R. Tapper ${ }^{1}$ and Gilles E. Martin ${ }^{1 *}$
}

1 Department of Psychiatry, The Brudnick Neuropsychiatric Research Institute, University of Massachusetts Medical School, Worcester, MA, USA, ${ }^{2}$ Gene Therapy Center, University of Massachusetts Medical School, Worcester, MA, USA, ${ }^{3}$ Department of Psychiatry, University of Illinois at Chicago, Chicago, IL, USA, ${ }^{4}$ Department of Anesthesiology, University of Pittsburgh, Pittsburgh, PA, USA

\section{OPEN ACCESS}

Edited by: Alessandro Tozzi,

University of Perugia, Italy

Reviewed by:

Carmelo Sgobio,

German Center

for Neurodegenerative Diseases,

Germany

Giuseppe Sciamanna, University of Rome Tor Vergata, Italy

${ }^{*}$ Correspondence: Gilles E. Martin gilles.martin@umassmed.edu

†These authors have contributed equally to this work.

Received: 28 November 2016 Accepted: 19 January 2017

Published: 13 February 2017

Citation:

Ji X, Saha S, Gao G, Lasek AW, Homanics GE, Guildford M, Tapper AR and Martin GE (2017) The Sodium Channel $\beta 4$ Auxiliary Subunit Selectively Controls Long-Term Depression in Core Nucleus Accumbens Medium Spiny Neurons. Front. Cell. Neurosci. 11:17. doi: 10.3389/fncel.2017.00017
Voltage-gated sodium channels are essential for generating the initial rapid depolarization of neuronal membrane potential during action potentials (APs) that enable cell-to-cell communication, the propagation of signals throughout the brain, and the induction of synaptic plasticity. Although all brain neurons express one or several variants coding for the core pore-forming sodium channel $\alpha$ subunit, the expression of the $\beta$ ( $\beta 1$ 4) auxiliary subunits varies greatly. Of particular interest is the $\beta 4$ subunit, encoded by the Scn4b gene, that is highly expressed in dorsal and ventral (i.e., nucleus accumbens NAc) striata compared to other brain regions, and that endows sodium channels with unique gating properties. However, its role on neuronal activity, synaptic plasticity, and behaviors related to drugs of abuse remains poorly understood. Combining whole-cell patch-clamp recordings with two-photon calcium imaging in Scn4b knockout (KO) and knockdown mice, we found that Scn4b altered the properties of APs in core accumbens medium spiny neurons (MSNs). These alterations are associated with a reduction of the probability of MSNs to evoke spike-timing-dependent long-term depression (tLTD) and a reduced ability of backpropagating APs to evoke dendritic calcium transients. In contrast, long-term potentiation (tLTP) remained unaffected. Interestingly, we also showed that amphetamine-induced locomotor activity was significantly reduced in male Scn4b KO mice compared to wild-type controls. Taken together, these data indicate that the Scn4b subunit selectively controls tLTD by modulating dendritic calcium transients evoked by backpropagating APs.

\footnotetext{
Keywords: nucleus accumbens, spike-timing-dependent plasticity, sodium channel, Scn $4 b$, knockout mice, calcium imaging, dendrites, long-term depression
}

\section{INTRODUCTION}

It has long been established that adaptation of organisms to their environment depends in part on neuron-to-neuron propagation of action potentials (APs) throughout the brain. More recently, research has provided clear evidence that APs, upon retrograde propagation into the dendritic compartment, also control induction of synaptic plasticity by interacting in a 
precise time-dependent fashion with excitatory post-synaptic potentials (Caporale and Dan, 2008; Sjostrom et al., 2008). In a previous work, using spike-timing-dependent plasticity (STDP) as a stimulation paradigm to induce synaptic plasticity, we showed that tLTP was tightly regulated by NMDA receptors while backpropagating APs and calcium-induced calcium release were key factors controlling tLTD (Ji and Martin, 2012). APs require the participation of sodium channels that control the initial fast rise of the membrane potential following an initial depolarization. These channels are formed by the association of a large pore-forming $\alpha$ subunit with accessory proteins or $\beta$ subunits (Catterall, 2000). Although a single $\alpha$ subunit forms the core of the channel and is functional on its own (Barchi, 1988), each of the various $\beta$ subunits ( $\beta 1-4)$ modulates $\alpha$ subunit gating properties in unique ways (Brackenbury and Isom, 2011). Of particular interest is the $\beta 4$ subunit, encoded by the Scn 4 b gene, as it prevents normal inactivation, conferring channels the ability to evoke a resurgent current upon repolarization (Grieco et al., 2005; Aman et al., 2009; Bant and Raman, 2010). While all brain neurons express one or more variants of the gene coding for the sodium channel $\alpha$ subunit (Goldin et al., 2000; Goldin, 2001), those expressing $\mathrm{Scn} 4 \mathrm{~b}$ are restricted to discreet brain regions particularly the dorsal striatum and the NAc (Oyama et al., 2006; Miyazaki et al., 2014), a structure known for mediating drugs of abuse's rewarding properties (Feltenstein and See, 2008). To date, the role of $\mathrm{Scn} 4 \mathrm{~b}$ beyond controlling sodium channel gating properties (Grieco et al., 2005; Aman et al., 2009; Huth et al., 2009; Bant and Raman, 2010) and spine density in hippocampal cultured neurons (Oyama et al., 2006) remains unclear. Here, we investigated its functional role in regulating synaptic plasticity in core NAc medium spiny neurons (MSNs). Using Scn $4 \mathrm{~b}$ shRNA and knockout mice (KO), we tested the hypothesis that manipulations of $\mathrm{Scn} 4 \mathrm{~b}$ expression in core NAc MSNs selectively impacts tLTD by modifying properties of APs, and by extension their ability to drive calcium signals in dendrites. We report that alterations of Scn $4 b$ expression significantly shifted APs threshold. This effect was associated with a large reduction of the probability of MSNs to induce tLTD, but not tLTP, in Scn4b KO and $\mathrm{KD}$ mice, irrespective of $\mathrm{D} 1$ dopamine receptor expression. Two-photon calcium imaging showed that backpropagating APdriven calcium signals was attenuated in second order dendrites of KO mice compared to wild type animals. Also, given the wellestablished role of the accumbens in mediating amphetamineinduced locomotor activity (Kelly et al., 1975; Pijnenburg et al., 1976), we tested whether alteration of the balance between tLTP and tLTD in mice lacking the Scn $4 b$ subunit impacted the effects of amphetamine on this behavior. Taken together, these data suggest that the $S c n 4 b$ subunit selectively controls tLTD formation by attenuating dendritic calcium transients following alteration of APs, effect that may be necessary for the psychostimulant action of amphetamine.

\section{MATERIALS AND METHODS}

B6.Cg-Tg(Drd1a-tdTomato) mice from Jackson laboratory, and $\mathrm{Scn} 4 \mathrm{~b} \mathrm{KO}$ mice (described below), were housed in an animal care facility approved by the American Association for the Accreditation of Laboratory Animal Care (AAALAC). We backcrossed B6.Cg-Tg(Drd1a-tdTomato) mice into the C57Bl/6 background. Animal experimental procedures were approved by the Institutional Animal Care and Use Committee of University of Massachusetts Medical School and the University of Pittsburgh. All efforts were made to minimize animal suffering and to reduce the number of animals used. Mice were housed four per cage and maintained at constant temperature and humidity with a 12-h light-dark cycle. Water and food were provided ad libitum.

\section{Targeting Vector Construction}

A 9745 bp Strain 129S7AB2.2 genomic DNA fragment harboring a portion of the Scn $4 b$ locus was subcloned from a BAC clone obtained from Source Bioscience (Nottingham, UK) into pStart-K using recombineering as described (Wu et al., 2008). Recombineering was also used to insert loxP/SalI sequences 199 bp upstream of Exon 2 and ScaI/loxP 266 bp downstream of Exon 2. SalI/frt flanked PGK-Neo derived from pK11 (Meyers et al., 1998) was subsequently subcloned into the SalI site that was introduced upstream of Exon 2. Gateway recombination was then used to move the modified Scn 4 b genomic DNA insert into pWSTK3 (Wu et al., 2008). The targeting construct was linearized with NotI for gene targeting. This construct included $5^{\prime}$ and $3^{\prime}$ arms of homology that were 4.1 and $5.0 \mathrm{~kb}$, respectively, and the floxed portion of the Scn $4 \mathrm{~b}$ locus was $647 \mathrm{bp}$.

\section{Gene Targeting in ES cells}

The linearized targeting construct was electroporated into R1 (Nagy et al., 1990) mouse embryonic stem (ES) cells as previously described (Homanics et al., 1997). G418 and gancyclovir resistant ES cell clones were screened for gene targeting by Southern blot analysis with EcoRI and a $5^{\prime}$ external probe $(\mathrm{Scn} 1+2)$ as illustrated in Supplementary Figure S1. Targeted clones were further analyzed with the following enzyme/probe combinations: EcoRV/Scn1+2; NdeI/Scn3+4; ScaI/Scn3+4; $\mathrm{SpeI} / \mathrm{Scn} 3+4$. Note that the ScaI analysis was also diagnostic for the presence/absence of the $3^{\prime}$ loxP site. $S c n 1+2$ is a 576 bp probe amplified (Primer $1=5^{\prime}$-ACTCCCCCGTGAACTCTTCT-3'; Primer $2=5^{\prime}$-TCTTACCCAAAAGCCCAGTG-3') from mouse genomic DNA and binds to Exon 1 . Scn3+4 is a 543 bp probe amplified (Primer $3=5^{\prime}$-TAAAAATTGCCCGTCTCCTG-3'; Primer $4=5^{\prime}$-GTGGAACATTCTCGCTGGTT-3' ${ }^{\prime}$ ) from mouse genomic DNA and binds to Exon 5 between the $3^{\prime}$ end of the targeting construct and the NdeI site. The results presented here are derived from ES cell clone 254B5.

\section{Scn4b Knockout Mouse Production}

Correctly targeted ES cell clones were microinjected into C57BL/6NCrl embryos (obtained as frozen embryos from Charles River) and subsequently implanted into pseduopregnant CD1 recipient females. Chimeric males were mated to C57BL/6J females. To create global KOs, F1 mice that were heterozygous for the floxed+neo locus were mated to EIIa-cre transgenic deleter mice (JAX stock \#003724; C57BL/6 background). F2 heterozygous, cre recombined mice were mated to $\mathrm{C} 57 \mathrm{BL} / 6 \mathrm{~J}$ 
mice to remove EIIa-cre from the pedigree. Mice were routinely genotyped by Southern blot analysis using NdeI and the Scn3+4 probe. Breeding pairs of cre recombined heterozygous $(+/ \mathrm{f})$ mice of the F3/N3 generation were shipped to UMass.

\section{Scn4b RT-PCR}

Wild type and global $\mathrm{KO}$ mice were sacrificed and tissue samples from cortex were isolated, flash frozen and stored at $-80 \mathrm{C}$ until processed. Total RNA was isolated from samples using Trizol (Life Technologies, Inc.). Approximately $1 \mu \mathrm{g}$ of RNA was converted to cDNA using an iScript cDNA Synthesis Kit (Bio-Rad Laboratories). Scn4b cDNAs were amplified using primers illustrated in Figure 1B (Primer $7=$ AACC GAGGCAATACTCAGGCGAGA; Primer 8 = AACCACTTGG AGGAAGATGGTGGCA; Primer $9=$ GGCAACCCGTTCT CTGTGTTGTCA; Primer 10 = TATCTGTGGGAAAGGCCA CCACCA) and Platinum Taq DNA Polymerase High Fidelity (Life Technologies). PCR cycling parameters were 95C $2 \mathrm{~min}$; 40 cycles of $95 \mathrm{C} 30 \mathrm{~s}, 60 \mathrm{C} 30 \mathrm{~s}$, and $72 \mathrm{C} 90 \mathrm{~s}$; and a final $72 \mathrm{C}$ 5 min extension. PCR products were analyzed on $2 \%$ agarose in TAE buffer with ethidium bromide.

\section{Scn4b Western Blot Analysis}

Brains from 10 weeks-old WT $(n=3)$ to $\mathrm{KO}(n=3)$ mice were dissected, the cerebellum removed, divided in half on the sagittal plane, and flash frozen. Membrane proteins were isolated from one half of each cerebellum using the MemPER Plus Extraction Kit (ThermoScientific, 89842). Protein lysates were concentrated through acetone precipitation and the concentration determined using a BCA assay. Thirty micrograms of protein lysate were loaded on a Novex 12\% Tris-Glycine gel (Invitrogen), electrophoresed, and transferred onto nitrocellulose using an iBlot Transfer Device (Invitrogen). Membranes were blocked in 5\%BSA/TBS for $1 \mathrm{~h}$ at RT and incubated overnight at $4^{\circ} \mathrm{C}$ with a primary monoclonal antibody (anti-SCN4b; UC Davis/NeuroMab facility, clone N168/6, \#75-198) at a dilution of $1: 4000$ in $5 \%$ BSA/TBS $+0.2 \%$ Tween 20 . Membranes were subsequently incubated with an IgG1 secondary fluorescent antibody according to manufacturer's instruction (Licor, \#92668050) and visualized using the Odyssey Infrared Imaging System (Licor Biosciences).

\section{Scn4b shRNA}

The Scn 4 b short hairpin RNA (shRNA) construct was designed using the siDesign Center (GE Dharmacon). The 19 nucleotide siRNA targeting sequence was incorporated into a hairpin sequence and cloned into pLL3.7 as previously described (16). The sequence of the 19 nucleotide targeting sequence is: $5^{\prime}$ GACCCTAAGGTGAGAGT-GA-3'. The shRNA was able to knockdown (KD) Scn $4 b$ mRNA in cell culture by $78 \%$ (data not shown). For adeno-associated virus (AAV) production, the Scn 4 b shRNA was excised from pLL3.7 and cloned into an AAV9 transfer vector, JHUMCS, derived from the original L307 vector (17) but lacking the IRES-GFP sequence. The AAV shRNA plasmid, ScAAV9.CB.eGFP.U6-ShScn4b-268, was packaged into AAV by the University of Massachusetts Medical School vector core facility. Briefly, HEK293 cells were transfected

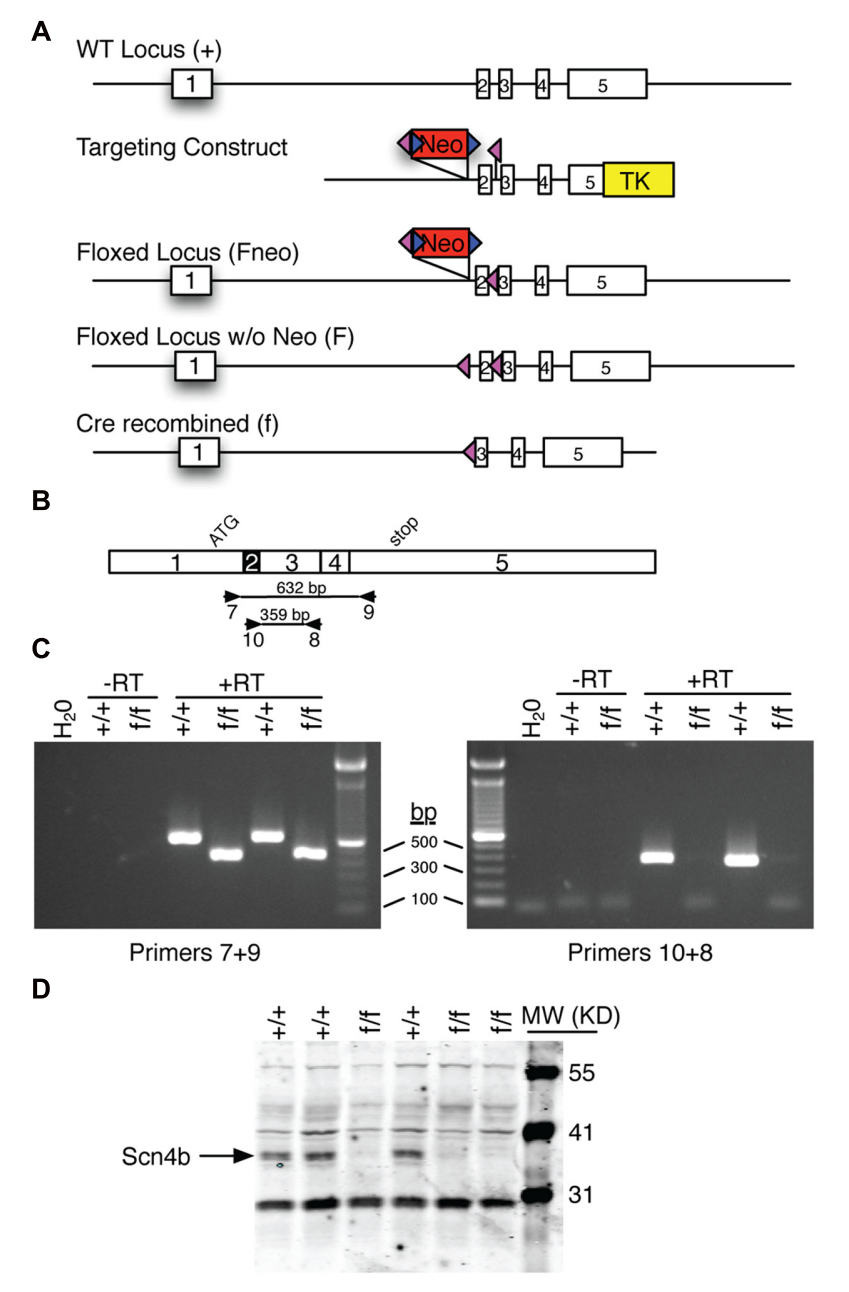

FIGURE 1 | Overview of Scn4b gene targeted mouse production. (A) Diagram of the various Scn4b loci. The wild type (WT) locus was modified in ES cells using the DNA targeting construct to create the floxed locus that includes the neomycin resistance (Neo) gene. Following germline transmission of this targeted locus, FLPe-mediated recombination was used to selectively remove the Neo gene. Cre-mediated recombination was used to remove Exon 2 of the Scn4b gene. (B) Diagram of the Scn4b cDNA showing exon boundaries, the start of translation (ATG), the translation termination codon (stop), PCR primer binding sites (numbered arrows), and the predicted size of PCR amplicons. (C) Photographs of agarose gel analysis of RT-PCR products from homozygous WT (+/+) and global KO (f/f) mouse cortex. Also included are water and minus reverse transcriptase (-RT) controls. In the left panel, WT products are $632 \mathrm{bp}$ as predicted. In contrast, products from f/f samples are $173 \mathrm{bp}$ smaller as predicted following deletion of Exon 2. In the right panel, Primers $10+8$ produced the 359 bp product only from WT samples; $f / f$ samples did not amplify with this primer set. (D) Western blot of cerebellar extracts with a Scn $4 b$ antibody. Note that the $\sim 37 \mathrm{KD}$ Scn $4 b$ protein is readily detected in $+/+$ samples. In contrast, no Scn $4 b$ is detected in $f / f$ samples.

with the transfer vector and three helper plasmids, pRSVREV, pIVS-vesicular stomatitis G protein (VSVg), and pMDL gag/pol. Transfected HEK293 cells were grown in neurobasal media and 2 days later the media was collected, spun at 2000 r.p.m. for $5 \mathrm{~min}$, and passed through a $0.45-\mathrm{mm}$ filter. The vector was injected in the nucleus accumbens of 21 day-old 
B6. $\operatorname{Cg}-\operatorname{Tg}$ (Drd1a-tdTomato) mice, and patch-clamp recordings were performed 3 weeks later.

\section{shRNA Knockdown Experiments}

Drdla-tdTomato mice were injected in the dorso-medial nucleus accumbens with virus and analyzed 3 weeks following injection. A number of MSNs in the vicinity of the injection site near the anterior commissure expressed GFP (Supplementary Figure S2A). At higher magnification, some GFP+ MSNs infected by the AAV9 virus are clearly visible (Supplementary Figure S2A, 40 $\times$ ). Among these GFP+ MSNs, some were also RFP+, indicative of dopamine D1 receptor expression (Supplementary Figure S2A, D1R+). qPCR performed on $1 \mathrm{~mm}$ wide disks of tissue containing the anterior commissure, the core accumbens landmark, showed that mRNA coding for the Scn 4 b subunit was significantly $[P<0.05$, and $F(2,2)=36.05]$ down regulated by $25 \%$ in mice injected with the Scn $4 \mathrm{~b}$ shRNAexpressing virus compared to mice injected with the control virus (Control, Supplementary Figure S2B). This value may not entirely reflect the full extent of Scn $4 \mathrm{~b}$ mRNA down regulation, since our tissue samples contained a sizable fraction of MSNs that were not infected by the virus as shown at low magnification (Data not shown).

\section{Animal Surgeries and Slice Preparation}

ScAAV9.CB.eGFP.U6-ShScn4b-268 construct was provided by Dr. E. Lasek and was packaged by UMass Medical School vector core facility. We anesthetized mice with a mixture of ketamine $(100 \mathrm{mg} / \mathrm{kg})$ and xylazine $(10 \mathrm{mg} / \mathrm{kg}$; VEDCO) before shaving and disinfecting the surgical area. Mice were placed in a stereotaxic frame (Stoelting Co., Wood Dale, IL, USA) and a small incision was cut in the scalp to expose the skull. Using Bregma and Lambda as landmarks, the skull was leveled in the coronal and sagittal planes. ScAAV9 virus $\left(1 \times 10^{12}\right.$ viral particles $/ \mathrm{ml}, 0.6 \mu \mathrm{l} /$ side) was injected bilaterally into NAc core region (Figure 1A); anterior-posterior (AP), $+1.5 \mathrm{~mm}$ from bregma; medial-lateral (ML), $\pm 1.2 \mathrm{~mm}$ from midline; dorsalventral (DV), $-6.5 \mathrm{~mm}$ from brain surface. The virus was injected at a flow rate of $0.1 \mu \mathrm{l} / \mathrm{min}$. The injection needle remained in place for $5 \mathrm{~min}$ post-injection before slowly being withdrawn. Mice were then returned to their home cages for 21 days before electrophysiology experiments.

\section{Slice Preparation and Electrophysiology}

To prepare slices from fresh brain tissue, we rapidly removed and transferred the brain in a cold $\left(\sim+0.5^{\circ} \mathrm{C}\right)$ oxygenated $\left(95 \% \mathrm{O}_{2}\right.$ and $5 \% \mathrm{CO}_{2}$ ) cutting solution of the following composition (in $\mathrm{mM}$ ): $95 \mathrm{~N}$-methyl-D-glucamine (NMDG), 2 thiourea, $5 \mathrm{Na}^{+}$ascorbate, $3 \mathrm{Na}^{+}$-pyruvate to cut $200 \mu \mathrm{m}$-thick slices transversely with a Vibroslicer (VT1200, Leica MicroInstrutments; Germany). Slices were immediately transferred in an incubation chamber and left to recuperate in the NMDG-based solution for $22 \mathrm{~min}$ at $32^{\circ} \mathrm{C}$ before being moved into a chamber containing an artificial cerebrospinal fluid (ACSF; in $\mathrm{mM}$ ): $126 \mathrm{NaCl}, 2.5 \mathrm{KCl}$, $\mathrm{NaH}_{2} \mathrm{PO}_{4} \cdot \mathrm{H}_{2} \mathrm{O}, 1 \mathrm{MgCl}_{2}, 2 \mathrm{CaCl}_{2}, 26 \mathrm{NaHCO}_{3}, 10$ D-Glucose, at room temperature. Slices were left in this chamber for at least $1 \mathrm{~h}$ before being placed in a recording chamber and perfused with ACSF at a constant rate of $2-3 \mathrm{ml} / \mathrm{min}$ at room temperature $\left(\sim 21^{\circ} \mathrm{C}\right)$. We visualized neurons in infrared differential interference contrast $(60 \times$, IR-DIC) video microscopy using a fully motorized microscope (Scientifica; England). We performed whole-cell patch clamp recordings. Briefly, we filled borosilicate glass electrodes $(1.5 \mathrm{~mm} \mathrm{OD}$, 4-6 $\mathrm{M} \Omega$ resistance) with an internal solution containing (in $\mathrm{mM}$ ): $120 \mathrm{~K}$-methanesulfonate, $20 \mathrm{KCl}, 10$ Hepes, $2 \mathrm{~K}_{2}$ ATP, 2 $\mathrm{K}_{2} \mathrm{GTP}$, and 12 phosphocreatine. Following seal rupture, series resistance (Rs 10-20 M $\Omega$ ) was fully compensated in currentclamp recording mode, and periodically monitored throughout recording sessions. Recordings with Rs changes larger than $20 \%$ were rejected. We acquired voltage and current traces in wholecell patch-clamp with an EPC10 amplifier (HEKA Elektronik; Germany). We sampled and filtered voltage and current traces acquired with PatchMaster 2.15 (HEKA Elektronik) at 10 and $2 \mathrm{kHz}$, respectively. We subsequently analyzed all traces off-line using FitMaster 2.15 (HEKA Electronik). To generate synaptic plasticity, we paired post-synaptic AP (evoked with a $5 \mathrm{~ms} / 6$ $800 \mathrm{pA}$ depolarizing pulse) followed by EPSP with a $20 \mathrm{~ms}$ interval at a rate of $1 \mathrm{~Hz}$ for $90 \mathrm{~s}$ as previously described (Ji and Martin, 2012). As previously described (Ji and Martin, 2012), we measured magnitude of synaptic plasticity by comparing EPSPs maximum amplitude in a $20 \mathrm{~ms}$ time window $10 \mathrm{~ms}$ before and after the onset of the stimulus. We performed this measurement on 30 consecutive EPSPs before, and $20 \mathrm{~min}$ after AP-EPSP pairing. We expressed the difference of EPSP amplitude before and after induction as percent of control (100\%). We performed statistical analysis on STDP and AP threshold, in Prism 5 (Graphpad, La Jolla, CA, USA) running on a Mac Power PC G5, with a one-way ANOVA followed by a Dunnett's post hoc test, with $P<0.05$ considered statistically significant. All averaged results are expressed as mean \pm SEM values.

\section{Two-Photon Laser Scanning (2PLSM) Calcium Imaging}

We filled recording pipettes with Fluo5F $(20 \mu \mathrm{M})$ and Alexa 549 (30 MM; Molecular Probes, Eugene, OR, USA). Dendritic locations were determined based on the loading of Alexa 594 after breaking into the cell (15-25 min). A custom-made 2PLSM (Scientifica, UK) with a Mai Tai HP Ti:Sapphire (SpectraPhysics, Santa Clara, CA, USA) laser providing pulses at $<100 \mathrm{fs}$ at $820 \mathrm{~nm}$ was used for imaging. Linescans along each dendritic location were performed using a $60 \mathrm{X}$ (1.0 NA) objective (Olympus). We recorded activity at various dendritic locations from the soma with clear branch points $\left(1^{\circ}=\right.$ primary, $2^{\circ}=$ secondary, $3^{\circ}=$ tertiary). Calcium transients were acquired using a standardized protocol controlled by Scanimage (Vidrio) that allowed the laser beam to be "parked" between each image capture. We used PatchMaster 2.15 (Germany) to evoke theta burst firing patterns in response to $800 \mathrm{pA}$ current injections to drive $\mathrm{Ca}^{2+}$ transients in MSNs. Only cells with stable resting membrane potential (RMP) between -82 and $-90 \mathrm{mV}$ were selected for recordings. All experiments were conducted at $32-34^{\circ} \mathrm{C}>15 \mathrm{~min}$ after break in. The protocol 

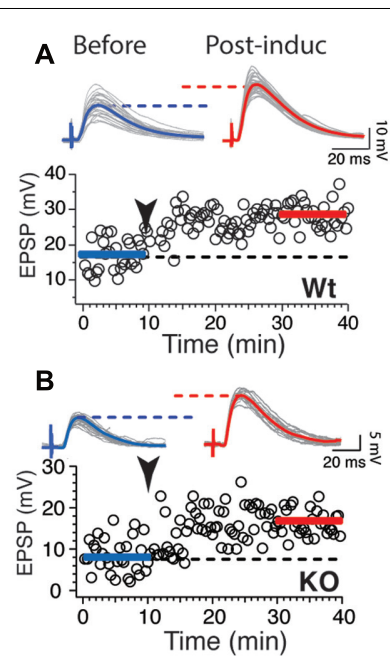

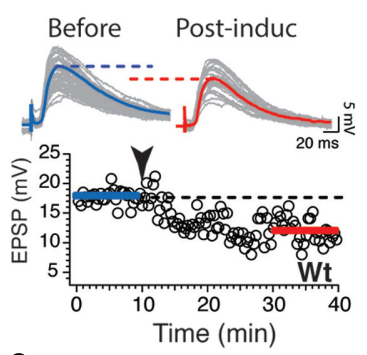

C

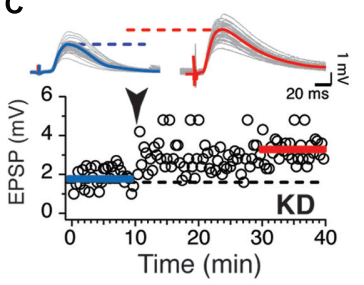

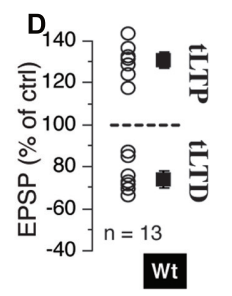

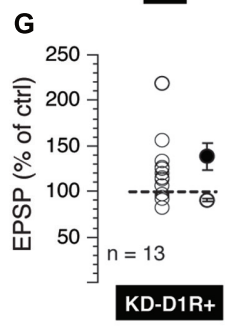

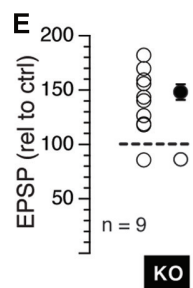

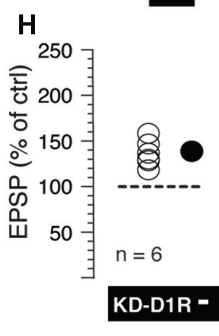

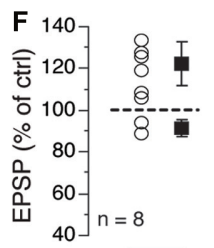

KD

I

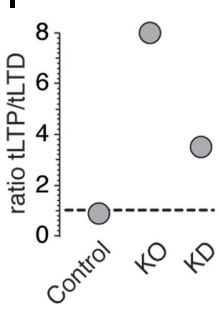

FIGURE 2 | Scn4b regulates induction of tLTD in NAc medium spiny neurons (MSNs). (A) Light gray overlapping traces show 30 consecutive EPSPs before (before) and after (post-induct) AP-EPSP pairing in two representative individual NAc MSNs from Control mice showing tLTP (left panel) and tLTD (right panel). Blue and red traces show averaged EPSP amplitudes before and after induction. Horizontal dashed lines are visual aids to compare the average EPSP amplitudes. Below, from the same neuron, graph of EPSPs amplitude monitored every $20 \mathrm{~s}$ before and after synaptic plasticity, respectively. Arrowhead indicates time of induction. (B,C) Representative examples of tLTP recorded in KO (left panel) and KD mice (right panel). (D) Each symbol indicates change of EPSP amplitude measured 20 min after induction in individual MSN. Symbols above and below dashed line show tLTP and tLTD, respectively. Change of synaptic strength after induction is expressed as percent of control (100\%). Solid symbols with SEM show averaged tLTP and tLTD. (E,F) As for panel D each symbol indicates change of synaptic strength in neurons recorded in KO and KD mice, respectively. (G,H) Plasticity in KD mice expressing D1R (G) or not (H). (I) Ratio of the number of MSNs evoking tLTP/tLTD in Control, KO and KD mice.

consisted of three consecutive potentials at a frequency of $5 \mathrm{~Hz}, 10 \mathrm{~s}$ intervals, at 42 frames per second. Fluorescence ratios were calculated based on $\Delta F=F / F_{0}$, where the baseline fluorescence $\left(F_{0}\right)$ was the average of first 20 frames. Three responses were averaged and then smoothed using SavitzkyGolay (first-order polynomial, $15 \mathrm{pt}$ ) filtering to acquire the individual calcium traces for each dendritic location. Slope of the rise of the signal was calculated as shown in Figure 4D. Maximum amplitude of the signal was captured for each calcium trace, within a limited response window of 15 frames following the baseline fluorescence. Statistical analysis of differences in dendritic calcium transients were established using the non-parametric Mann-Whitney test, and were considered significant if $P<0.05$. Error bars shown are SEM. All analysis was conducted using custom-written code in MATLAB (MathWorks).

\section{Behavior}

Scn 4 b KO males $(n=8)$ and their wild-type litter mates $(n=6)$ were i.p. injected with $100 \mu \mathrm{L}$ saline in their homecage for 2 days prior to the start of the experiment to habituate to injections. On the 3rd day, mice were placed in a novel cage situated in a locomotor activity apparatus (Photobeam Activated System, San Diego Instruments, San Diego, CA, USA) for $1 \mathrm{~h}$ to habituate to the cage and to measure baseline activity. Following the habitation period, mice were injected with saline and placed back in the cage for an additional hour of locomotor activity measurements (data not shown). On days 4 and 5, mice were again placed in a novel cage for an hour of habituation and baseline activity measurements before being injected with either saline or $5 \mathrm{mg} / \mathrm{kg}$ amphetamine (D-amphetamine sulfate in saline, Sigma-Aldrich, MI). Injections were cross-balanced across genotype and day. For each day, activity was measured as the number of beam breaks over the indicated time-course, with baseline defined as the total activity $10 \mathrm{~min}$ after the start of the experiment until injections, and the experimental measurements from 10 min post-injection until the end of the experiment. Experimental activity results are presented as a percent of baseline activity. We used a 2-way ANOVA and a post hoc analysis to test statistical significance.

\section{RESULTS}

To study the role of Scn4b on MSNs physiology, we used gene targeting (Figure 1A) and ES cell technologies to create mice in which Exon 2 of the Scn 4 b gene was flanked by loxP sites (i.e., floxed). Floxed mice were crossed with a cre general deleter mouse line to recombine the targeted locus and delete Exon 2. To verify that cre recombination disrupts the $S \mathrm{cn} 4 \mathrm{~b}$ gene, mRNA from cortex was analyzed by RT-PCR (Figures 1B,C) using two primer sets. Primers $7+9$ which bind to Exons 1 and 5 , respectively, revealed the expected $632 \mathrm{bp}$ fragment from WT mice. In contrast, these primers produced a $459 \mathrm{bp}$ from KO samples as predicted for deletion of the $173 \mathrm{bp}$ Exon 2. Primers $8+10$ which bind to Exons 3 and 2, respectively, revealed the expected $359 \mathrm{bp}$ fragment only from WT samples. KO samples did not yield a PCR product with this primer set. This result is also consistent with deletion of Exon 2. Deletion of Exon 2 is predicted to create a frameshift mutation and result in a truncated Scn $4 b$ 
product that is 20 amino acids plus 9 non-sense amino acids. Full length Scn4b is 228 amino acids. Western blot analysis of cerebellar extracts using a $\mathrm{Scn} 4 \mathrm{~b}$ selective antibody confirmed the absence of the $\sim 37 \mathrm{KD} \mathrm{Scn} 4 \mathrm{~b}$ protein in $\mathrm{KO}$ samples (Figure 1D; Supplementary Figure S1).

\section{The Scn4b Subunit Expression Selectively Regulates the Expression of tLTD}

In a previous study, we showed that accumbens tLTD is governed by somatic APs, a phenomenon that is blocked by intracellular calcium chelators, and L-type calcium channels antagonists (Ji and Martin, 2012). Given the key role of sodium channels in shaping APs, we hypothesized that $S \mathrm{cn} 4 \mathrm{~b}$ regulates the expression of tLTD by altering APs properties. In Control mice, 90 consecutive APs - EPSPs pairings $(20 \mathrm{~ms}$ delay at $1 \mathrm{~Hz}$ ) induced both tLTP (Figure 2A, left panel) and tLTD (Figure 2A, right panel) in equal proportion (tLTP, $n=6$; tLTD, $n=7$ ). While tLTP amplitude was $131.5 \pm 3.67$, that of tLTD was $69.33 \pm 4.8 \%$ of control (Figure 2D), similar to what we previously reported in similar experimental conditions (Ji and Martin, 2012). In KO mice, the vast majority expressed a robust tLTP $(151.8 \pm 7.9 \%$, $n=8$; Figures $2 \mathrm{~B}, \mathrm{E}$ ), while only one MSNs showed a weak depression (Figure 2E). In mice injected with AAV-shRNA (KD) targeting Scn4b expression (Supplementary Figure S2), tLTP was also the predominant form of plasticity (Figures 2C,F), while weak tLTD was observed in only two MSNs (93\% of control, Figure 2F). In order to determine whether this effect was related to the expression of dopamine receptors, we also injected $\mathrm{Scn} 4 \mathrm{~b}$ shRNA in B6 DAR1-tdTomato BAC transgenic mice, and recorded from MSNs expressing $(\mathrm{D} 1 \mathrm{R}+)$ or not $(\mathrm{D} 1 \mathrm{R}-)$ dopamine D1 receptors. We found that the expression of D1 receptors has no clear influence on synaptic plasticity in shRNA mice as it was remarkably similar in both D1R+ and D1Rneuronal populations (Figures 2G,H). Thus, most MSNs D1R+ $(n=9)$ and D1Rs $-(n=6)$ MSNs evoked tLTP $(137.71 \pm 14.37$; $136.56 \pm 13.94 \%$ of control, respectively), tLTD $(89.80 \pm 2.33 \%)$ was observed in only four MSNs in D1R+ MSNs (Figure $\mathbf{2 H}$ ), and none in D1R-MSNs (Figure $2 \mathrm{H} ; n=6$ ). Statistical analysis shows a significance $[F(2,45)=5.15 ; p=0.0096]$. Post hoc analysis showed a significant difference of threshold in $\mathrm{KO}$ compared to wild type $(p=0.0054)$, but not between Wt and KD $(p=0.058)$. To quantify the probability of MSNs to induce tLTP and tLTD, we calculated the ratio of the number of tLTP/tLTD MSNs, with the number 1 indicating perfect parity between both forms of plasticity. In Control mice, the ratio was 0.85 , pointing to a slightly higher probability of evoking tLTD over tLTP (Figure 2I). However, in Scn $4 \mathrm{~b} \mathrm{KO}$ and $\mathrm{KD}$ mice, a ratio of 8 and 4 , respectively, indicated a dramatic shift in favor of tLTP (Figure 2I).

Having shown that $\mathrm{Scn} 4 \mathrm{~b}$ expression controls the probability of tLTD induction, we set out to determine whether this effect was associated with changes in AP properties, the main factor contributing to tLTD formation (Ji and Martin, 2012). Figure 3A shows side-by-side representative examples of 90 overlaid APs recorded during induction in control, Scn $4 \mathrm{~b} \mathrm{KO}$

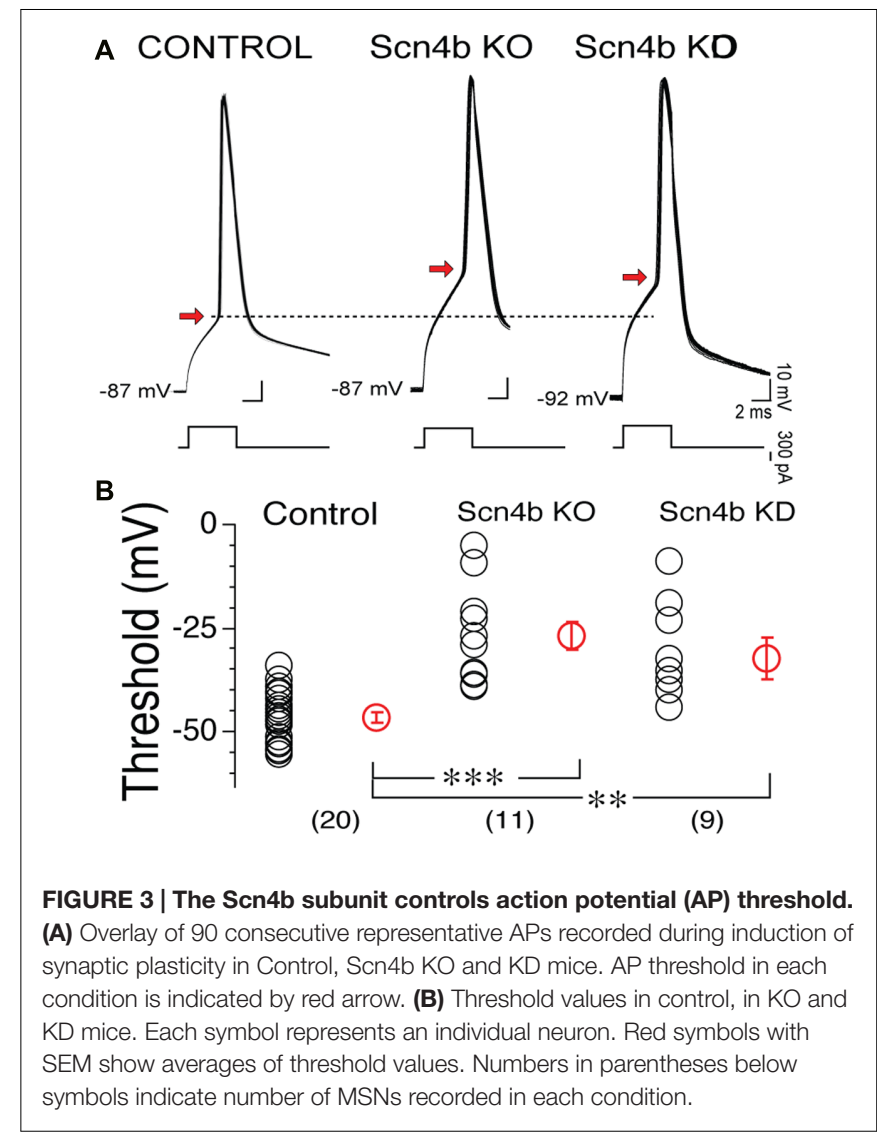

and KD mice. In Scn $4 \mathrm{~b}$ KO and KD animals, AP threshold (red arrowhead) was noticeably more depolarized compared Control mice (Figure 3A). Averaging threshold values in these various experimental conditions confirmed this initial observation. Thus, AP threshold in Control mice was $-46.39 \pm 3.69 \mathrm{mV}$ (Figure 3B, control; $n=20)$. In Scn $4 \mathrm{~b} \mathrm{KO}$ mice $(n=11)$ and KD mice $(n=9)$, it was markedly shifted toward less negative potential of $-26.69 \pm 3.27 \mathrm{mV}$ and $-32.11 \pm 4.91 \mathrm{mV}$, respectively (Figure 3B). A one-way ANOVA statistical analysis showed a significant difference of threshold between $\mathrm{Wt}, \mathrm{KO}$, and $\mathrm{KD}$ $[F(2,42)=20.9 ; p<0.0001]$. Post hoc analysis showed a significant difference of threshold in $\mathrm{KO}$ and $\mathrm{KD}$ mice compared to wild type with $p$-values of 0.0001 and 0.002 , respectively (Figure 3B). Neither MSNs RMPs nor their input resistance (Rin) were significantly affected in $\mathrm{KO}$ mice, while their currentvoltage relationship was smaller in $\mathrm{KO}$ compared to wt mice (Supplementary Figure S3).

\section{Scn4b Expression Controls Backpropagating AP-Evoked Dendritic Calcium Signal}

Although our data suggest that the Scn $4 b$ subunit controls tLTD induction, how the former influences the latter was unclear. One putative path connecting $\mathrm{Scn} 4 \mathrm{~b} / \mathrm{APs}$ and tLTD was calcium. In freshly isolated MSNs, as somatic APs invade dendrites (Figures 4A,C), through an active process due in part to the 

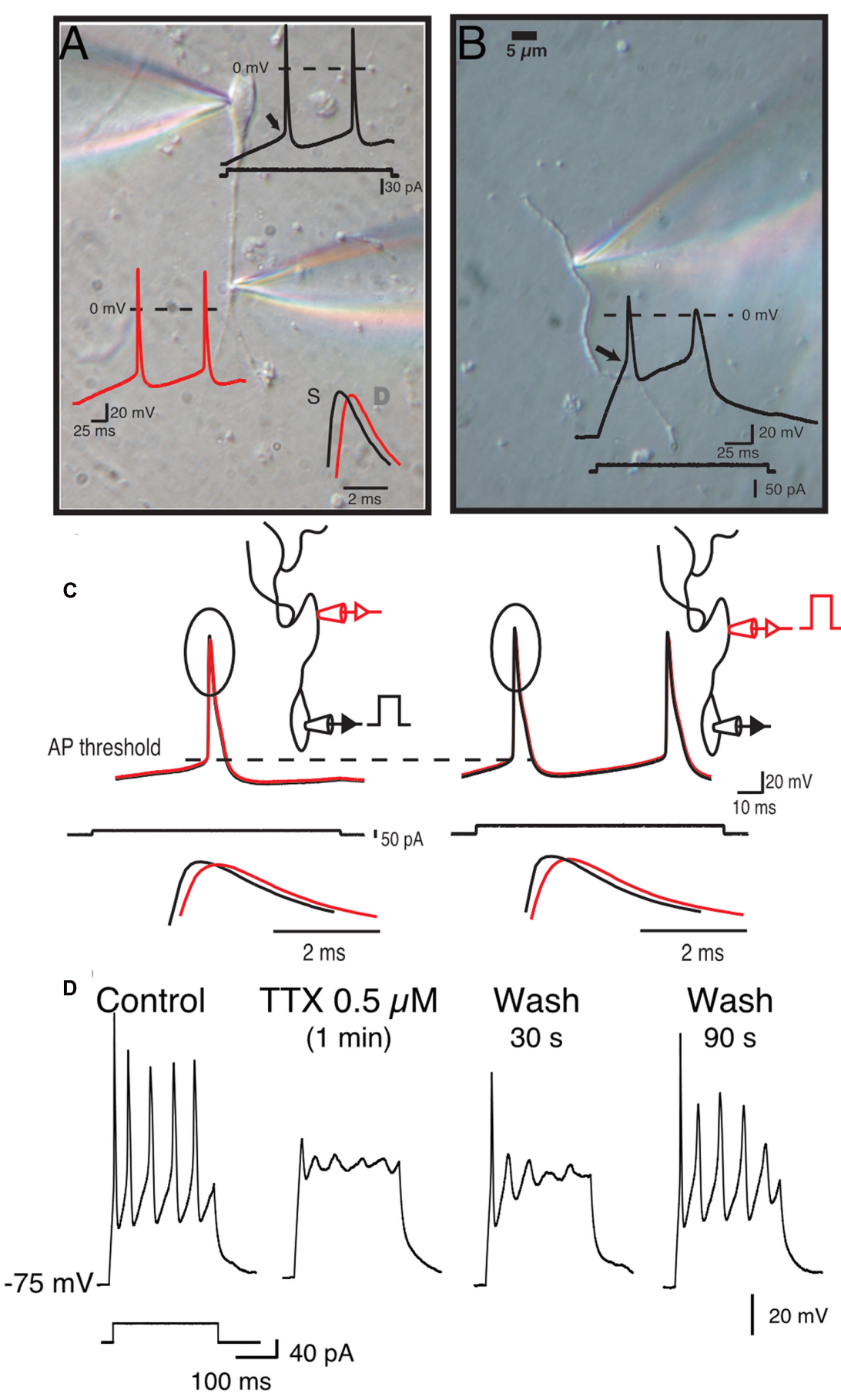

FIGURE 4 | Medium spiny neurons dendrites express sodium channels and backpropagating APs. (A) Simultaneous double somatic and dendritic recordings on a freshly isolated MSN. Current step was injected in the soma and voltage was recorded in soma (black trace) and dendrite (white trace). Note the delay between the peaks of the first somatic and dendritic APs. (B) Voltage in response of a current step injected in an isolated dendrite. Note the much higher threshold (arrow head) and small overshoot (star) of dendritic APs. (C) Initiation of APs is somatic regardless of where the current step is injected (i.e., somatic left panels, or dendritic right panels). (D) APs recorded in isolated dendrites are totally and reversibly blocked by $0.5 \mu \mathrm{M} T \mathrm{TX}$.

expression of TTX-sensitive sodium channels in MSNs dendrites (Figures 4B,D), they generate calcium transients (Plotkin et al., 2013). Having shown that AP-driven calcium-induced calcium release during synaptic induction is necessary for tLTD
(Ji and Martin, 2012), we tested whether Scn4b expression controls the ability of APs to drive dendritic calcium transients. Combining two-photon laser scanning microscopy with patch clamp recordings, we measured calcium signals, driven by theta 

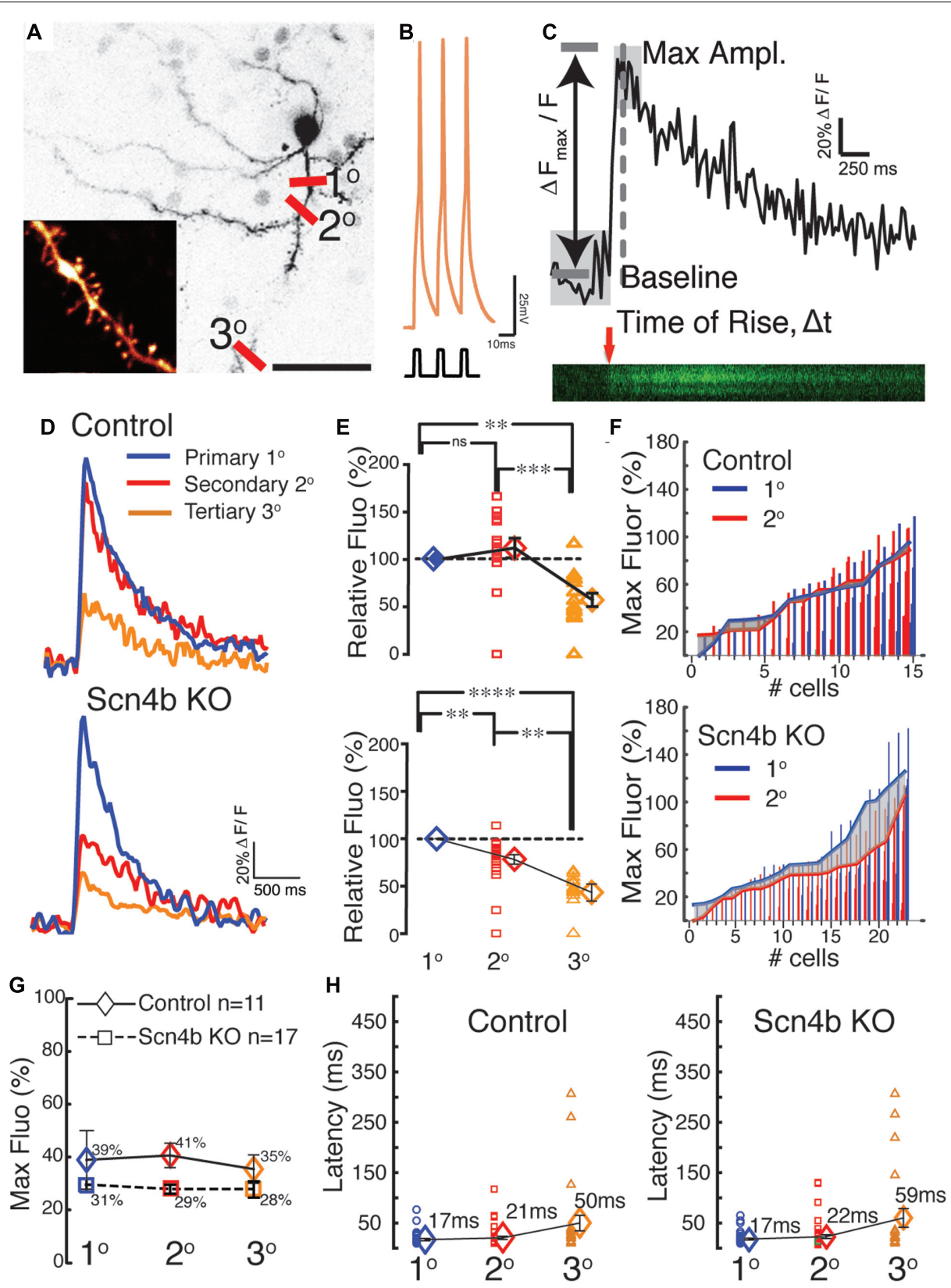

FIGURE 5 | Scn4b controls the amplitude of calcium signals evoked by backpropagating APs. (A) Maximum intensity projection of soma and dendritic areas in a MSN. Red lines indicate the approx. dendritic sites $\left(1^{\circ}=\right.$ primary, $2^{\circ}=$ secondary, $3^{\circ}=$ tertiary $)$ where $\mathrm{Ca}^{2+}$ transients were measured as PLSM linescans for each MSN, which were visualized using Alexa 594. Scale $=30 \mu \mathrm{m}$. (B) Representative theta burst firing pattern in response to $800 \mathrm{pA}$ current injections used to drive the $\mathrm{Ca}^{2+}$ transients in $\mathrm{MSNs}(\mathrm{RMP}=-85 \mathrm{mV})$. (C) A representative raw $\mathrm{Ca}^{2+}$ trace from three linescans from a $2^{\circ}$ dendritic site expressed as $\Delta \mathrm{F}_{\text {max }} / \mathrm{F}$. Calculations for rising slope and maximum amplitude were based on the $t$-value and the average of the baseline signal. (D) Representative S-G filtered Ca ${ }^{2+}$ response recorded in $1^{\circ}, 2^{\circ}$, and $3^{\circ}$ dendrites resulting from a theta burst in Control (top panel) and $\mathrm{KO}$ mice (bottom panel). (E) Amplitude of $\mathrm{Ca}^{2+}$ transients in $2^{\circ}$ (red symbols), and $3^{\circ}$ dendrites (orange symbols) normalized to calcium responses measured in $1^{\circ}$ dendrites (100\%; blue symbols) in Control (top graph) and $\mathrm{KO}$ mice (bottom graph). Each symbol represents a neuron. (F) Maximum amplitude of $\mathrm{Ca}^{2+}$ responses from $1^{\circ}$ (blue) to $2^{\circ}$ (red) dendritic shown in ascending order in individual cells. The relationship of the $\mathrm{Ca}^{2+}$ signal between primary and secondary dendrites is shown by the solid lines which represents the average max amplitude of $\mathrm{Ca}^{2+}$ responses of the dendritic locations. The shaded area highlights the incongruity of the $\mathrm{Ca}^{2+}$ signal, which is more pronounced in the larger $\mathrm{Ca}^{2+}$ transients of the Scn $4 \mathrm{~b} \mathrm{KO}$ in comparison to control animals where the transients are closely matched between $1^{\circ}$ and $2^{\circ}$ dendrites. (G) Mean values of maximal $\mathrm{Ca}^{2+}$ transients measured in spines expressed as percent of calcium transients in the corresponding dendritic shaft in Control (diamonds) and KO mice (Squares). Red triangles show averages. $(\mathbf{H})$ Latency of calcium maximal fluorescence responses in $1^{\circ}, 2^{\circ}$, and $3^{\circ}$ dendrites. Latencies indicate that measurements were collected at similar distances along dendrites in both the Control and Scn $4 \mathrm{~b}$ KO groups. 
burst APs evoked somatically (Figure 5B), along the dendritic arbor in first $\left(1^{\circ}\right)$, second $\left(2^{\circ}\right)$, and third $\left(3^{\circ}\right)$ order dendrites (Figure 5A). Dendritic calcium signals, a proxy for measuring the strength of backpropagating APs, were characterized by a rapid rise followed by a slow decay (Figure 5C). The decay time course of the transients, where the $\Delta \mathrm{F}$ returned to basal levels, (Figure 5D) was relatively indistinguishable when comparing dendritic arborizations (Control $1^{\circ}: 2.97 \mathrm{~s}, 2^{\circ}: 2.96 \mathrm{~s}, 3^{\circ}: 2.62 \mathrm{~s}$, KO $\left.1^{\circ}: 3 \mathrm{~s}, 2^{\circ}: 2.65 \mathrm{~s}, 3^{\circ}: 2.37 \mathrm{~s}\right)$, with small changes in $\mathrm{KO}$ mice that were not statistically significant. In Control mice, amplitude of calcium transients remained relatively stable, increasing slightly to $112.1 \pm 10.37 \%$ in $2^{\circ}$ dendrites relative to $1^{\circ}$ processes (Figure 5E, top graph, red symbols). However, we observed a significant decline in $3^{\circ}$ dendrites as the calcium signal dropped to $57.427 \pm 7.08 \%$ (Figure 5E, orange symbols). Statistical analysis revealed a significant difference between $2^{\circ}$ and $3^{\circ}$ $(p=0.00082)$ and $1^{\circ}$ and $3^{\circ}$ dendrites $(p=0.0024)$ only. In KO mice, although the calcium signal similarly decreased between the $1^{\circ}$ and $3^{\circ}$ dendrites, the drop of amplitude was already detectable in $2^{\circ}$ dendrites compared to $1^{\circ}$ dendrites (78.22 $\pm 5.04 \%$, Figures 5E,F, lower panels), an effect that was significant $(p=0.0108)$, unlike in Control mice $(p=0.092)$. The amplitude of calcium transients further declined in $3^{\circ}$ processes (43.41 $\pm 8.97 \%$; Figure 5E, orange symbols, $p=0.0086)$. The distribution of responses across cells shows that the attenuation of calcium transients (Figure 5F, gray area) in second order dendrites (Figure 5F, red line) of KO mice was mostly observed in $1^{\circ}$ dendrite where calcium transients were stronger (gray area). Although calcium transients were robustly attenuated between dendritic shaft and spine heads (no attempts were made to distinguish between the different spine morphologies) in $1^{\circ}, 2^{\circ}$, and $3^{\circ}$ dendrites in both control and $\mathrm{KO}$ mice, a statistical analysis showed no difference between the two conditions (Figure 5G). Figure 5H, showing the latency between APs and calcium signals onsets in control and $\mathrm{KO}$ mice, indicates that changes of the amplitude of calcium signals are unlikely the result of transients being recorded at different distances from the soma. Finally, in shRNA mice, the calcium signal was also significantly depressed compared to Control in all dendritic compartments (not shown).

\section{Amphetamine-Induced Locomotor Activity Is Reduced in Scn4b KO Mice}

The accumbens is a key region mediating psychostimulantsevoked locomotor activity (Kelly et al., 1975; Pijnenburg et al., 1976). Considering the robust expression of Scn $4 b$ in this brain region, we tested whether its absence and the lack of tLTD affected $\mathrm{KO}$ mice response to amphetamine. In wild type (Control) and KO mice, locomotor activity remained stable, rising only slightly after injection of saline in both groups (Figure 6A, top graph). However, it rose sharply and reached a maximum 15-20 min following a single injection of $5 \mathrm{mg} / \mathrm{kg}$ amphetamine (green arrowhead, Figure 6A lower panel), before returning to control levels 50 min post-injection (Figure 6A, open red symbols). In KO mice $(n=8)$, while the locomotor activity also rose during the first few minutes following the injection, it peaked

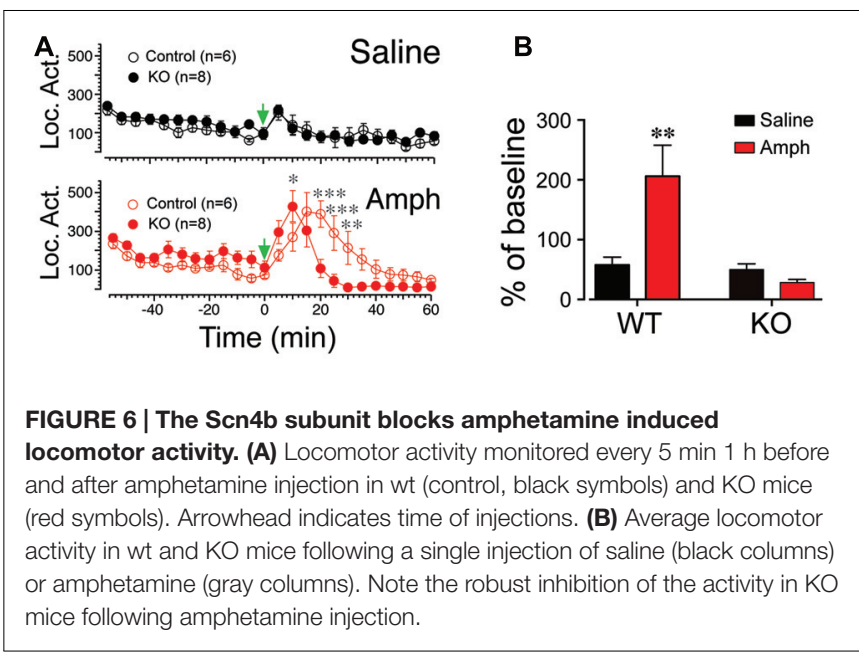

(i.e., $10 \mathrm{~min}$ post-injection) and declined much faster within 20 min (Figure 6A, KO, solid red circles). A two-way ANOVA revealed a significant main effect of time $[F(23,276)=15.39$; $p<0.0001]$ and a significant time $\times$ genotype interaction $[F(23,276)=6.629 ; p<0.0001]$. Post hoc analysis showed a significant difference of amphetamine on locomotor activity in KO mice compared to wild type at $10,20,25$, and $30 \mathrm{~min}$ (Figure 6B). Also, averaged over $1 \mathrm{~h}$ post-amphetamine injection, locomotor activity was significantly reduced in $\mathrm{KO}$ compared to wild type mice ( $p=0.003$; Amph, Figure 6B). Activity of wild type and $\mathrm{KO}$ mice were similar following saline injection (Figure 6B, Saline).

\section{DISCUSSION}

We provide for the first time, evidence indicating that low or no Scn $4 \mathrm{~b}$ expression dramatically impairs the ability of NAc MSNs to evoke tLTD, a consequence of attenuated dendritic calcium transients. More specifically, in absence of the subunit, APs evoked during induction of plasticity are characterized by a large shift of the AP threshold. Functionally, the ability of APs to drive calcium transients in dendrites is attenuated in KO mice, an effect mostly observed in secondary dendrites. Finally, the locomotor stimulating properties of amphetamine was significantly attenuated in $\mathrm{KO}$ mice.

Although there is still little known about the contribution of Scn $4 \mathrm{~b}$ on the sodium channel biophysical properties, some evidence suggest that the channel $1 / 2$ max voltage activation is in part under the control of this subunit. Thus, in HEK cells, the voltage dependence of activation of peak sodium channel core subunit $\mathrm{Na}_{\mathrm{v}} 1.1$ was markedly shifted to the right (i.e., toward less negative potentials) in absence of the subunit, while the channel inactivation remains unaffected (Aman et al., 2009), confirming a previous study in tsA-201 cells transfected with the $\mathrm{Na}_{\mathrm{v}} 1.2$ core $\alpha$ subunit ( $\mathrm{Yu}$ et al., 2003). These findings could explain in part the shift of AP threshold reported in our study. However, because this shift in HEK cells is noticeably smaller (i.e., $+3-6 \mathrm{mV}$ ) than the change of threshold in MSNs 
from $\mathrm{KO}$ mice (i.e., $+20 \mathrm{mV}$ ), it is unlikely that the lack of Scn $4 b$ alone accounts for such difference. A number of additional factors may influence the threshold value, among them changes in the ion conductance as well as density of voltagegated sodium and potassium that can either raise or lower value of threshold (Trautwein, 1963). MSNs may compensate the loss of $S c n 4 b$ by overexpressing the $S c n 2 b$, an auxiliary subunit commonly expressed in the striatum unlike Scn1b and $3 \mathrm{~b}$, possibly conferring biophysical properties to sodium channels unseen in wild type animals. However, in situ hybridization experiment showed that $\mathrm{Scn} 2 \mathrm{~b}$ expression only marginally increased in Scn4b KO mice (Miyazaki et al., 2014). Another possibility may involve potassium channels recruited during APs. Recently, Marionneau et al. (2012) showed that the expression of $\mathrm{Kv} 4.2$, a major constituent of fast inactivating $\mathrm{I}_{\mathrm{A}}$ channels that is highly expressed in the NAc, decreases in neurons lacking the sodium channel Scn 1 b subunit in layer 5 cortical pyramidal neurons (Marionneau et al., 2012). Finally, MSNs may adapt to a lack of Scn $4 b$ by lowering the expression of the sodium channel pore-forming $\alpha$ subunit.

Voltage-gated calcium channels activated during AP-driven depolarization are likely responsible for dendritic calcium transients as their expression is typically not limited to the soma but also extend to dendrites where they contribute to the active backpropagation of APs along with sodium channels, in a number of brain regions (Markram and Sakmann, 1994; Magee and Johnston, 1995; Kavalali et al., 1997), including the striatum (Carter et al., 2007; Shindou et al., 2011). Nevertheless, they are unlikely to be the only source of calcium modulated in the absence of Scn $4 \mathrm{~b}$. Indeed, in a previous study, we showed that, upon entering MSNs through L-type calcium channels, an additional pool of calcium is released from intracellular endoplasmic reticulum stores following activation of ryanodine receptors (Ji and Martin, 2012). Therefore, the decrease of the amplitude of dendritic calcium transients in $\mathrm{KO}$ and $\mathrm{KD}$ mice, that may result from a lesser contribution of VGCC, may be amplified by a weaker calcium-induced calcium release. Perhaps similar amplitudes of calcium signals in primary dendrites in Control and $\mathrm{KO}$ mice suggest that if a change of AP threshold is necessary it is not be sufficient, and that other downstream factors may contribute to shaping dendritic calcium signals.

While it remains to be elucidated how a shift of AP threshold impact calcium transients in $\mathrm{KO}$ and $\mathrm{KD}$ mice, it is likely that the significant drop in calcium in secondary dendrites is responsible for a diminished tLTD. We previously reported that tLTD resulted from the release of cannabinoids binding on CB1 receptors expressed on glutamatergic terminals (Ji and Martin, 2012), confirming previous reports in the striatum (Sadikot et al., 1998; Hoffman et al., 2003; Robbe et al., 2003; Fourgeaud et al., 2004) and other brain regions (Sjostrom et al., 2003; Safo and Regehr, 2005; Peterfi et al., 2012). The role of calcium as a factor critical to tLTD formation is supported by data from the dorsal striatum showing it is inhibited by blocking L-type calcium channels and ryanodine receptors (Plotkin et al., 2013). Furthermore, pairing of uncaged glutamate-mediated EPSPs with APs in dorsal striatum MSNs produced supralinear increase in spine $\left[\mathrm{Ca}^{2+}\right]_{\mathrm{i}}$ (Shindou et al., 2011). Interestingly, this effect was only associated with tLTD. Surprisingly, no change of $\left[\mathrm{Ca}^{2+}\right]_{\mathrm{i}}$ was observed during tLTP. This study not only highlights the central role played by calcium in mediating APs-mediated tLTD, but also supports the contention that a decrease of calcium transients in dendrites would directly dampen tLTD, as observed here.

Behaviorally, amphetamine-induced locomotion was significantly reduced in $\mathrm{KO}$ mice, a phenomenon that is likely the result of a direct involvement of the NAc considering the key role of this brain region in mediating the effects of psychostimulants on locomotion (Kelly et al., 1975; Pijnenburg et al., 1976). Although our study focused on the ventral striatum, we cannot rule out the possibility that the dorsal striatum, a brain region where $S \mathrm{cn} 4 \mathrm{~b}$ is also highly expressed and that receives dense dopaminergic innervations from the substantia nigra, may also be implicated in the stark behavioral response observed in $\mathrm{KO}$ mice. Additionally, in light of the fact that one of amphetamine's modes of action is to influence dopamine release through the dopamine transporter expressed on presynaptic dopaminergic terminals in striatum (Robertson et al., 2009; Daberkow et al., 2013; Underhill et al., 2014), it is conceivable that the response of $\mathrm{KO}$ mice to amphetamine may also indirectly reflect altered excitability of dopaminergic VTA neurons. Indeed, these neurons are innervated by projecting from pyramidal neurons originating in the prefrontal cortex, neurons that also express the Scn 4 b subunit. Although it is unclear how the Scn 4 b subunit influences locomotion, inhibition of MSNs firing, as shown in a recent study (Miyazaki et al., 2014), may limit MSNs ability to send information to downstream regions. Alternatively, in light of recent optogenetic-based research in mice showing that fear-related memory can be reactivated and inactivated by LTP and LTD, respectively (Nabavi et al., 2014, \#104743), the reduced tLTD probability in NAc MSNs lacking the Scn4b subunit could be interpreted as the inability to erase memories formed during exposure to drugs of abuse, and more specifically when these drugs subvert the neurocircuitry that includes the NAc, to mediate rewards to drugs of abuse (Kelley and Berridge, 2002; Volkow et al., 2008). Of particular interest is the markedly altered expression of mRNA coding for the Scn 4 b subunit in alcohol-preferring mice and rats (Mulligan et al., 2006; Tabakoff et al., 2008), and more recently in populations of alcoholics (Farris et al., 2014). These studies point to $S \mathrm{cn} 4 \mathrm{~b}$ as a possible pathway mediating the effects of EtOH on memory related to drugs of abuse rewarding properties. Further studies are needed to better understand how this sodium channel subunit regulates the physiology of MSNs and the role of the NAc in relation with psychostimulants, and more generally with all drugs of abuse.

\section{AUTHOR CONTRIBUTIONS}

AWL designed and produced the Snc4b shRNA. GEH provided the $\mathrm{Scn} 4 \mathrm{~b}$ KO mice. XJ performed electrophysiological experiments and analyzed data. SS performed calcium imaging experiments and analyzed data. MG performed behavioral experiments. ART helped design experiments and edited the 
manuscript. GG provided the adeno associated virus from UMass core viral facility. GEM designed the experiments and wrote the manuscript.

\section{ACKNOWLEDGMENTS}

This work was supported by the National Institute of Alcohol Abuse and Addiction AA020501 (GEM), AA020889 (GEH), AA016654 (AWL), AA017656 (ART), AA022567 (MG), and the Integrative Neuroscience Initiative on Alcoholism (INIA-West; GEM, GEH, and AWL).

\section{SUPPLEMENTARY MATERIAL}

The Supplementary Material for this article can be found online at: http://journal.frontiersin.org/article/10.3389/fncel. 2017.00017/full\#supplementary-material

\section{REFERENCES}

Aman, T. K., Grieco-Calub, T. M., Chen, C., Rusconi, R., Slat, E. A., Isom, L. L., et al. (2009). Regulation of persistent Na current by interactions between beta subunits of voltage-gated Na channels. J. Neurosci. 29, 2027-2042. doi: 10.1523/ JNEUROSCI.4531-08.2009

Bant, J. S., and Raman, I. M. (2010). Control of transient, resurgent, and persistent current by open-channel block by Na channel beta4 in cultured cerebellar granule neurons. Proc. Natl. Acad. Sci. U.S.A. 107, 12357-12362. doi: 10.1073/ pnas. 1005633107

Barchi, R. L. (1988). Probing the molecular structure of the voltage-dependent sodium channel. Annu. Rev. Neurosci. 11, 455-495. doi: 10.1146/annurev.ne. 11.030188 .002323

Brackenbury, W. J., and Isom, L. L. (2011). Na channel beta subunits: overachievers of the ion channel family. Front. Pharmacol. 2:53. doi: 10.3389/fphar.2011. 00053

Caporale, N., and Dan, Y. (2008). Spike timing-dependent plasticity: a hebbian learning rule. Annu. Rev. Neurosci. 31, 25-46. doi: 10.1146/annurev.neuro.31. 060407.125639

Carter, A. G., Soler-Llavina, G. J., and Sabatini, B. L. (2007). Timing and location of synaptic inputs determine modes of subthreshold integration in striatal medium spiny neurons. J. Neurosci. 27, 8967-8977. doi: 10.1523/JNEUROSCI. 2798-07.2007

Catterall, W. A. (2000). From ionic currents to molecular mechanisms: the structure and function of voltage-gated sodium channels. Neuron 26, 13-25. doi: 10.1016/S0896-6273(00)81133-2

Daberkow, D. P., Brown, H. D., Bunner, K. D., Kraniotis, S. A., Doellman, M. A., Ragozzino, M. E., et al. (2013). Amphetamine paradoxically augments exocytotic dopamine release and phasic dopamine signals. J. Neurosci. 33, 452-463. doi: 10.1523/JNEUROSCI.2136-12.2013

Farris, S. P., Arasappan, D., Hunicke-Smith, S., Harris, R. A., and Mayfield, R. D. (2014). Transcriptome organization for chronic alcohol abuse in human brain. Mol. Psychiatry 20, 1438-1447. doi: 10.1038/mp.2014.159

Feltenstein, M. W., and See, R. E. (2008). The neurocircuitry of addiction: an overview. Br. J. Pharmacol. 154, 261-274. doi: 10.1038/bjp.2008.51

Fourgeaud, L., Mato, S., Bouchet, D., Hemar, A., Worley, P. F., and Manzoni, O. J. (2004). A single in vivo exposure to cocaine abolishes endocannabinoidmediated long-term depression in the nucleus accumbens. J. Neurosci. 24, 6939-6945. doi: 10.1523/JNEUROSCI.0671-04.2004

Goldin, A. L. (2001). Resurgence of sodium channel research. Annu. Rev. Physiol. 63, 871-894. doi: 10.1146/annurev.physiol.63.1.871

Goldin, A. L., Barchi, R. L., Caldwell, J. H., Hofmann, F., Howe, J. R., Hunter, J. C., et al. (2000). Nomenclature of voltage-gated sodium channels. Neuron 28, 365-368. doi: 10.1016/S0896-6273(00)00116-1
FIGURE S1 | Details of Scn4b genotype analysis. Shown are the various loci that were genotyped by Southern blot analysis. Included are relevant restriction sites, probes, and drug selectable markers (Neo, neomycin resistance; TK, thymidine kinase). Magenta and blue triangles represent loxP and frt sites, respectively. The floxed locus w/o Neo can be used to create conditional knockouts. The cre recombined locus lacks Exon 2 and constitutes a global knockout. Not all aspects of diagram are drawn to scale.

FIGURE S2 | Scn4b ShRNA decreases Scn4b mRNA expression in core NAc MSNs. (A) Image of a slice of tissue stained with GFP antibody indicates location of injection (10x). (B) At higher magnification $(40 \times)$ individual GFP+ cells are clearly visible. In the same slice, double staining with a RFP antibody shows neurons expressing D1 receptors. (C) Quantification of mRNA coding for the Scn4b subunit in mice injected with the Control and shRNA-containing virus $(\operatorname{shRNA})$. The symbol * indicates $p<0.05$.

FIGURE S3 | Effects of Scn4b expression on MSNs resting potential and input resistance. (A) Graph shows resting membrane potential of MSNs from wild type (Wt) and Scn4b knockout mice (KO). Each symbol represents a MSN. Red dotted lines and bars show mean values and SEM, respectively. (B) Same as A for MSNs input resistance. (C) Current voltage relationship in wild type (wt), knockdown (KD), and knockout (KO) mice. Note the strong effect of Scn4b on the voltage in response to depolarizing current steps.

Grieco, T. M., Malhotra, J. D., Chen, C., Isom, L. L., and Raman, I. M. (2005). Openchannel block by the cytoplasmic tail of sodium channel beta4 as a mechanism for resurgent sodium current. Neuron 45, 233-244. doi: 10.1016/j.neuron.2004. 12.035

Hoffman, A. F., Oz, M., Caulder, T., and Lupica, C. R. (2003). Functional tolerance and blockade of long-term depression at synapses in the nucleus accumbens after chronic cannabinoid exposure. J. Neurosci. 23, 4815-4820.

Homanics, G. E., Ferguson, C., Quinlan, J. J., Daggett, J., Snyder, K., Lagenaur, C., et al. (1997). Gene knockout of the $\alpha 6$ subunit of the $\gamma$-aminobutyric acid type A receptor: lack of effect on responses to ethanol, pentobarbital, and general anesthetics. Mol. Pharmacol. 51, 588-596. doi: 10.1124/mol.51.4.588

Huth, T., Schmidt-Neuenfeldt, K., Rittger, A., Saftig, P., Reiss, K., and Alzheimer, C. (2009). Non-proteolytic effect of beta-site APP-cleaving enzyme 1 (BACE1) on sodium channel function. Neurobiol. Dis. 33, 282-289. doi: 10.1016/j.nbd.2008. 10.015

Ji, X., and Martin, G. E. (2012). New rules governing synaptic plasticity in core nucleus accumbens medium spiny neurons. Eur. J. Neurosci. 36, 3615-3627. doi: 10.1111/ejn.12002

Kavalali, E. T., Zhuo, M., Bito, H., and Tsien, R. W. (1997). Dendritic Ca2+ channels characterized by recordings from isolated hippocampal dendritic segments. Neuron 18, 651-663. doi: 10.1016/S0896-6273(00)80305-0

Kelley, A. E., and Berridge, K. C. (2002). The neuroscience of natural rewards: relevance to addictive drugs. J. Neurosci. 22, 3306-3311.

Kelly, P. H., Seviour, P. W., and Iversen, S. D. (1975). Amphetamine and apomorphine responses in the rat following 6-OHDA lesions of the nucleus accumbens septi and corpus striatum. Brain Res. 94, 507-522. doi: 10.1016/ 0006-8993(75)90233-4

Magee, J. C., and Johnston, D. (1995). Characterization of single voltage-gated Na+ and $\mathrm{Ca} 2+$ channels in apical dendrites of rat CA1 pyramidal neurons. J. Physiol. 487, 67-90. doi: 10.1113/jphysiol.1995.sp020862

Marionneau, C., Carrasquillo, Y., Norris, A. J., Townsend, R. R., Isom, L. L., Link, A. J., et al. (2012). The sodium channel accessory subunit Navbetal regulates neuronal excitability through modulation of repolarizing voltage-gated $\mathrm{K}(+)$ channels. J. Neurosci. 32, 5716-5727. doi: 10.1523/JNEUROSCI.6450-11.2012

Markram, H., and Sakmann, B. (1994). Calcium transients in dendrites of neocortical neurons evoked by single subthreshold excitatory postsynaptic potentials via low-voltage-activated calcium channels. Proc. Natl. Acad. Sci. U.S.A. 91, 5207-5211. doi: 10.1073/pnas.91.11.5207

Meyers, E. N., Lewandoski, M., and Martin, G. R. (1998). An Fgf8 mutant allelic series generated by Cre- and Flp-mediated recombination. Nat. Genet. 18, 136-141. doi: 10.1038/ng0298-136

Miyazaki, H., Oyama, F., Inoue, R., Aosaki, T., Abe, T., Kiyonari, H., et al. (2014). Singular localization of sodium channel beta4 subunit in unmyelinated fibres and its role in the striatum. Nat. Commun. 5:5525. doi: 10.1038/ncomms6525 
Mulligan, M. K., Ponomarev, I., Hitzemann, R. J., Belknap, J. K., Tabakoff, B., Harris, R. A., et al. (2006). Toward understanding the genetics of alcohol drinking through transcriptome meta-analysis. Proc. Natl. Acad. Sci. U.S.A. 103, 6368-6373. doi: 10.1073/pnas.0510188103

Nabavi, S., Fox, R., Proulx, C. D., Lin, J. Y., Tsien, R. Y., and Malinow, R. (2014). Engineering a memory with LTD and LTP. Nature 511, 348-352. doi: 10.1038/ nature 13294

Nagy, A., Gócza, E., Diaz, E. M., Prideaux, V. R., Iványi, E., Markkula, M., et al. (1990). Embryonic stem cells alone are able to support fetal development in the mouse. Development 110, 815-821.

Oyama, F., Miyazaki, H., Sakamoto, N., Becquet, C., Machida, Y., Kaneko, K., et al. (2006). Sodium channel beta4 subunit: down-regulation and possible involvement in neuritic degeneration in Huntington's disease transgenic mice. J. Neurochem. 98, 518-529. doi: 10.1111/j.1471-4159.2006. 03893.x

Peterfi, Z., Urban, G. M., Papp, O. I., Nemeth, B., Monyer, H., Szabo, G., et al. (2012). Endocannabinoid-mediated long-term depression of afferent excitatory synapses in hippocampal pyramidal cells and GABAergic interneurons. J. Neurosci. 32, 14448-14463. doi: 10.1523/JNEUROSCI.1676-12. 2012

Pijnenburg, A. J., Honig, W. M., Van der Heyden, J. A., and Van Rossum, J. M. (1976). Effects of chemical stimulation of the mesolimbic dopamine system upon locomotor activity. Eur. J. Pharmacol. 35, 45-58. doi: 10.1016/00142999(76)90299-5

Plotkin, J. L., Shen, W., Rafalovich, I., Sebel, L. E., Day, M., Chan, C. S., et al. (2013). Regulation of dendritic calcium release in striatal spiny projection neurons. J. Neurophysiol. 110, 2325-2336. doi: 10.1152/jn.00422.2013

Robbe, D., Alonso, G., and Manzoni, O. J. (2003). Exogenous and endogenous cannabinoids control synaptic transmission in mice nucleus accumbens. Ann. N. Y. Acad. Sci. 1003, 212-225. doi: 10.1196/annals.1300.013

Robertson, S. D., Matthies, H. J., and Galli, A. (2009). A closer look at amphetamine-induced reverse transport and trafficking of the dopamine and norepinephrine transporters. Mol. Neurobiol. 39, 73-80. doi: 10.1007/s12035009-8053-4

Sadikot, A. F., Burhan, A. M., Belanger, M. C., and Sasseville, R. (1998). NMDA receptor antagonists influence early development of GABAergic interneurons in the mammalian striatum. Dev. Brain Res. 105, 35-42. doi: 10.1016/S01653806(97)00148-X

Safo, P. K., and Regehr, W. G. (2005). Endocannabinoids control the induction of cerebellar LTD. Neuron 48, 647-659. doi: 10.1016/j.neuron.2005.09.020
Shindou, T., Ochi-Shindou, M., and Wickens, J. R. (2011). A Ca(2+) threshold for induction of spike-timing-dependent depression in the mouse striatum. J. Neurosci. 31, 13015-13022. doi: 10.1523/JNEUROSCI.3206-11.2011

Sjostrom, P. J., Rancz, E. A., Roth, A., and Hausser, M. (2008). Dendritic excitability and synaptic plasticity. Physiol. Rev. 88, 769-840. doi: 10.1152/physrev.00016. 2007

Sjostrom, P. J., Turrigiano, G. G., and Nelson, S. B. (2003). Neocortical LTD via coincident activation of presynaptic NMDA and cannabinoid receptors. Neuron 39, 641-654. doi: 10.1016/S0896-6273(03)00476-8

Tabakoff, B., Saba, L., Kechris, K., Hu, W., Bhave, S. V., Finn, D. A., et al. (2008). The genomic determinants of alcohol preference in mice. Mamm. Genome 19, 352-365. doi: 10.1007/s00335-008-9115-z

Trautwein, W. (1963). Generation and conduction of impulses in the heart as affected by drugs. Pharmacol. Rev. 15, 277-332.

Underhill, S. M., Wheeler, D. S., Li, M., Watts, S. D., Ingram, S. L., and Amara, S. G. (2014). Amphetamine modulates excitatory neurotransmission through endocytosis of the glutamate transporter EAAT3 in dopamine neurons. Neuron 83, 404-416. doi: 10.1016/j.neuron.2014.05.043

Volkow, N. D., Wang, G. J., Fowler, J. S., and Telang, F. (2008). Overlapping neuronal circuits in addiction and obesity: evidence of systems pathology. Philos. Trans. R. Soc. Lond. B Biol. Sci. 363, 3191-3200. doi: 10.1098/rstb.2008. 0107

Wu, S., Ying, G., Wu, Q., and Capecchi, M. R. (2008). A protocol for constructing gene targeting vectors: generating knockout mice for the cadherin family and beyond. Nat. Protoc. 3, 1056-1076. doi: 10.1038/nprot.2008.70

Yu, F. H., Westenbroek, R. E., Silos-Santiago, I., McCormick, K. A., Lawson, D., Ge, P., et al. (2003). Sodium channel beta4, a new disulfide-linked auxiliary subunit with similarity to beta2. J. Neurosci. 23, 7577-7585.

Conflict of Interest Statement: The authors declare that the research was conducted in the absence of any commercial or financial relationships that could be construed as a potential conflict of interest.

Copyright (c) 2017 Ji, Saha, Gao, Lasek, Homanics, Guildford, Tapper and Martin. This is an open-access article distributed under the terms of the Creative Commons Attribution License (CC BY). The use, distribution or reproduction in other forums is permitted, provided the original author(s) or licensor are credited and that the original publication in this journal is cited, in accordance with accepted academic practice. No use, distribution or reproduction is permitted which does not comply with these terms. 